\title{
ELECTRON BEAM WELDABILITY OF DAMAGE-TOLERANT TITANIUM ALLOY TC21
}

\author{
YUAN HONG, ZHANG GUO-DONG, WANG JIN-XUE, YU HUAI and ZHU ZHI-SHOU \\ Beijing Institute of Aeronautical Materials \\ 100095, Beijing, China. E-mail: hong.yuan@biam.ac.cn
}

\begin{abstract}
In China TC21 alloy represents itself $\alpha+\beta$ titanium alloys with tensile strength of $1100 \mathrm{MPa}$, high fracture toughness and low fatigue crack growth rate. The study of EBW of thick-section TC21 alloy was carried out and mechanical properties of welded joints were evaluated. Testing of fracture toughness and resistance to fatigue crack reveal that their damage tolerance is comparable to that of base metal. The high cycle fatigue strength of the EB-welded joints is $643 \mathrm{MPa}$, reaching $98.3 \%$ of that of base metal. The microstructure of weld metal consists of coarse columnar dendritic prior $\beta$-grains and finer acicular $\alpha$-martensite, which accounts for the difference of crack growth rate and fracture toughness between base metal and metal of welded joints. These results indicate that TC21 titanium alloy has excellent EB weldability. 8 Ref., 1 Table, 9 Figures.
\end{abstract}

Ke y words : electron beam welding, damage tolerance, fracture toughness, fatigue crack propagation

Titanium alloys are widely used in the airframe and critical systems because of their specific strength, resistance to fatigue, high temperature and environmental effects [1]. The design methods change markedly influenced titanium alloy development direction and promoted development of high damagetolerant titanium, which possesses high fracture toughness and low crack propagation rate $[2,3]$.

In China TC2 1 alloy represents itself $\alpha+\beta$ titanium alloys with tensile strength of $1100 \mathrm{MPa}$, which has the excellent damage tolerance, high fracture toughness exceeding $90 \mathrm{MPa} \cdot \mathrm{m}^{2}$ and low fatigue crack propagation rate $d a / d N$ up to $9 \cdot 10^{-6} \mathrm{~mm} /$ cycle at $\Delta K=11 \mathrm{MPa} \cdot \sqrt{\mathrm{m}}(R=0.1)$. The alloy underwent manufacturing processing for composition optimizing, melt purifying, as weld as quasi- $\beta$ forging and heat treatment to achieve specific strength and fracture toughness of not less than thouse of alloy Ti1023. This indicates that alloy can be selected as the first-class material to manufacture the important support structures of airframes for advanced aircraft, where EBW technology will be of great necessity to assemble the airframe components of damage-tolerant titanium alloy.

In present work, the thermal simulation experiments, simulated EBW thermal cycles with various welding speed, were carried out for evaluation of dependencies of properties of welded joints on different welding line energy and various cooling rates. So we could acquaint with the EB weldability of TC21 alloy whether or not sensible to welding heat input. Results of the research will be directed to optimization of
EBW parameters and postweld heat processing. The comparison of mechanical properties of EB-welded joints gained by varying welding speed symbolizing welding heat input character corresponds to the thermal simulation experiments. EBW conditions for $60 \mathrm{~mm}$ thickness TC21 alloy were studied, and the damage tolerance properties of the joints, such as fracture toughness and resistance to fatigue crack propagation, were evaluated.

Materials and experimental procedure. The base material used for simulation and welding experiments in this work is TC21 titanium alloy forged by quasi- $\beta$ forging process with subsequent solution heat treatment $\left(900{ }^{\circ} \mathrm{C}, 2 \mathrm{~h}\right.$, air cooling). Chemical compositions of the material was as follows, wt.\%: $5.8 \mathrm{Al}-2.0 \mathrm{Sn}-2.0 \mathrm{Zr}-2.8 \mathrm{Mo}-2.0 \mathrm{Nb}-1.7 \mathrm{Cr}-0.1 \mathrm{Si}$, and $\mathrm{Ti}$ - balance.

EBW simulation experiments conducted in Gleeble 1500 thermal simulator system were carried out by imposing thermal cycles on a series of square-section specimens. The specimens were cut from the forgings and machined up to $10 \times 10 \times 55 \mathrm{~mm}$ size. The simulation tests were performed at rapid heating rate of $1000{ }^{\circ} \mathrm{C} / \mathrm{s}$ to preset peak temperature of $1200{ }^{\circ} \mathrm{C}$ for constant holding time of $40 \mathrm{~s}$, followed by different cooling rate of $0.1,0.5,5,25,80^{\circ} \mathrm{C} / \mathrm{s}$ (air cooling), and $160{ }^{\circ} \mathrm{C} / \mathrm{s}$ (water cooling) individually. The dimension of isothermal zone (or working zone) is about $8-10 \mathrm{~mm}$ across the middle of the specimen. The specimens simulated were machined to the samples for tensile strength and impact toughness tests at room temperature according to standard ISO 
9016:2001. Charpy impact fracture toughness tests were performed in full-scale U-notch specimens.

Full penetration EBW was performed on KL106 machine, imported from E.O. Paton Electric Welding Institute, with medium accelerating voltage of $60 \mathrm{kV}$. The EBW parameters used given in the Table. The welding speeds for TC21 alloy $14 \mathrm{~mm}$ thick were selected from 4 to $25 \mathrm{~mm} / \mathrm{s}$ that matched with suitable beam current in order to obtain the diversity of heat input. After welding, non-destructive testing was carried out to detect possible defects in the welded joints. The defect-free plates were selected to prepare specimens for evaluation their metallographic and mechanical properties.

The specimens for metallographic and tensile tests, which were cut from the EB-welded joints $14 \mathrm{~mm}$ thick, were prepared to evaluate the effect of welding heat input on their microstructure and mechanical properties. The $60 \mathrm{~mm}$ thick base metal and EB-welded joints were heat treated by duplex annealing $\left(900{ }^{\circ} \mathrm{C}, 2 \mathrm{~h}\right.$, air cooling $+590{ }^{\circ} \mathrm{C}, 4 \mathrm{~h}$, air cooling). Subsequently, the specimens for tests on tensile, Charpy U-notch impact, fracture toughness, high cycle fatigue and fatigue crack growth rate were machined according to ISO standards to compare the degradation of damage-tolerant properties of the EB-welded joints and base metal. The notch root of all the EB-welded joint specimens was located at the weld metal centre.

Specimens for metallurgical tests were grinded, polished, etched and examined by Olympus GX51 optical microscope. A more detailed microstructural characteristic study was carried out by using FEI Quanta600 scanning electron microscope.

Tensile and Charpy U-notch impact tests were carried out on Instron-5887 electron universal test machine and ANS ZBC2302 impact test machine, respectively. Plane strain fracture toughness testing was carried on MTS-370 electro-hydraulic servo machine employing compact tension (CT) specimens of $25 \mathrm{~mm}$ thickness and $60 \mathrm{~mm}$ width. Stress-amplitude controlled high-cycle fatigue tests were performed using a sinusoidal waveform at stress ratio $R=0.06$. Plain cylindrical specimens were tested on QBG-50 electro-magnetic resonance testing machine at frequency of $115 \mathrm{~Hz}$. Tests were terminated either by failure or not failing when $10^{7}$ cycles were achieved. Fatigue crack growth (FCG) tests were conducted at constant $R=0.06$ and frequency of $10 \mathrm{~Hz}$ on CT specimens with dimensions of 62.5 (length) $\times 50$ (width) $\times$ $\times 12.5$ (thickness) $\mathrm{mm}$.

Results and discussion. Thermal simulation. The stable simulating procedure was stable and was repeated while more than 3 samples were performed
EBW parameters at $U_{\text {acc }}=60 \mathrm{kV}$ and $l_{\text {work }}=150 \mathrm{~mm}$

\begin{tabular}{|c|c|c|c|c|}
\hline $\begin{array}{c}\text { Plate } \\
\text { thick- } \\
\text { ness, } \mathrm{mm}\end{array}$ & $\begin{array}{c}\text { Beam } \\
\text { current, } \\
\mathrm{mA}\end{array}$ & $\begin{array}{c}\text { Welding } \\
\text { speed, } \\
\mathrm{mm} / \mathrm{s}\end{array}$ & $\begin{array}{c}\text { Focus } \\
\text { current, } \\
\mathrm{mA}\end{array}$ & $\begin{array}{c}\text { Heat } \\
\text { input, } \\
\mathrm{J} / \mathrm{mm}\end{array}$ \\
\hline \multirow{3}{*}{14} & 165 & 25 & 830 & 396 \\
\cline { 2 - 5 } & 110 & 12 & 830 & 550 \\
\cline { 2 - 5 } & 70 & 4 & 830 & 1050 \\
\hline 60 & 290 & 6 & 855 & 2900 \\
\hline
\end{tabular}

at the same thermal simulation parameters. Figure 1 shows the tensile and impact properties of the Gleeble-simulated specimens at different cooling rate. The strength values increase monotonously with the increasing of cooling rate, while the ductility and impact toughness change in the opposite way. Specimens at $v_{\text {cool }}==0.1$ and $0.5{ }^{\circ} \mathrm{C} / \mathrm{s}$ have excellent ductility and impact toughness, whereas their tensile strength is relatively low. The mechanical properties change dramatically, when cooling rate increase from 0.5 to $5{ }^{\circ} \mathrm{C} / \mathrm{s}$, especially it is characteristic for impact toughness, which decreased from 42 to $9 \mathrm{~J} / \mathrm{cm}^{2}$. In particular, with increasing cooling rate from 5 to $160{ }^{\circ} \mathrm{C} / \mathrm{s}$, the degradation of ductility and impact toughness is not obvious.

It is clear that the approving cooling rate is controlled by less than $0.5{ }^{\circ} \mathrm{C} / \mathrm{s}$ to achieve high comprehensive mechanical properties at EB processing, whereas the cooling rates of less than $0.5{ }^{\circ} \mathrm{C} / \mathrm{s}$ is impossible to put into practice in fusion welding. Therefore, the conclusion was drawn that TC21 alloy is not sensitive to welding heat input and postweld weld cooling rates, especially in EBW - high energy density welding method. The microstructure and mechanical properties of the joints can't be improved evidently by the methods of meliorating the welding parameters and welding line energy, such as to solve the problem of getting back the missing ductility and toughness, and so on.

Effect of heat input on macrostructure and mechanical properties of EB-welded joints. The micro-

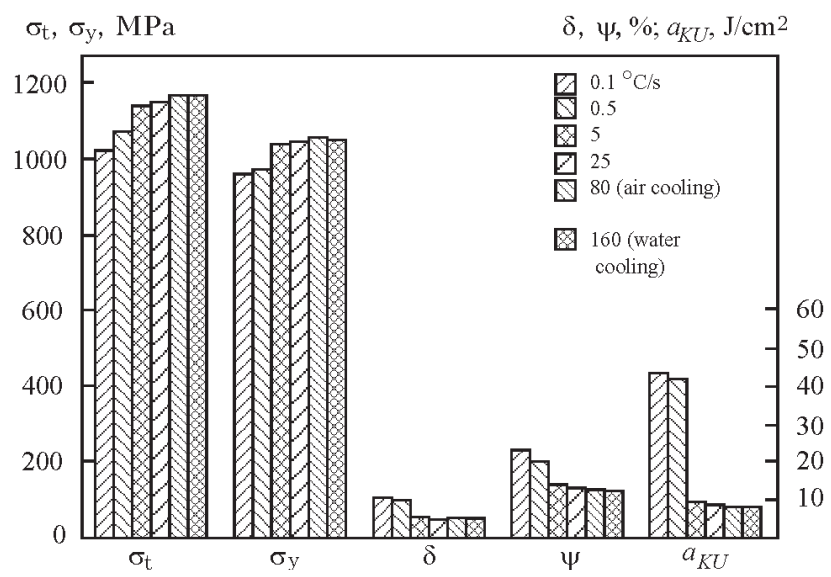

Figure 1. Tensile and impact properties of the Gleeble-simulated specimens at different cooling rate 


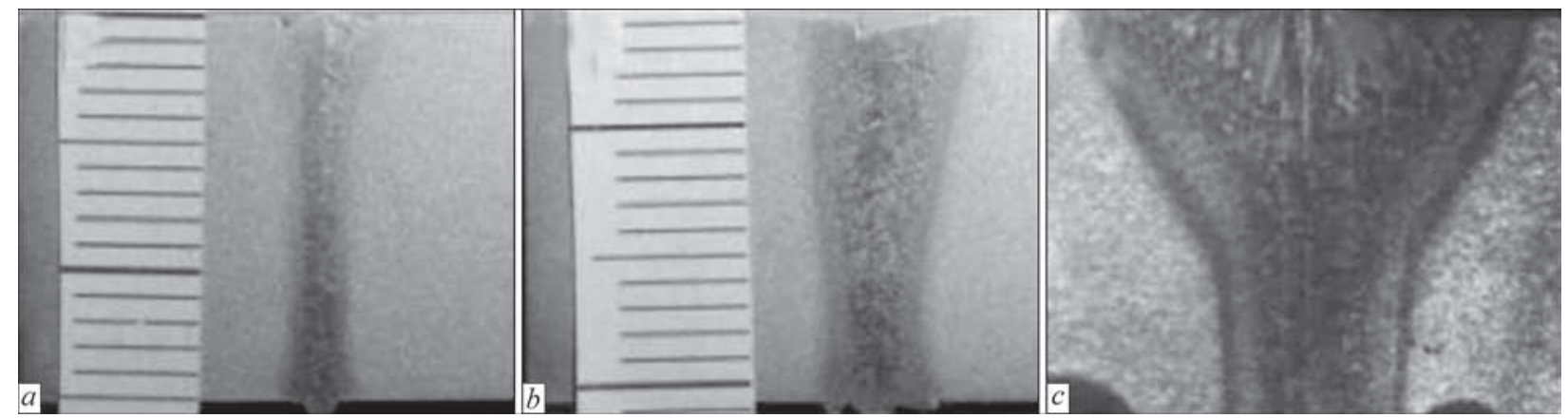

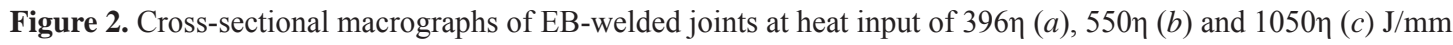

structures and mechanical properties of joints are primarily determined by the results of phase transformation, such as arrangement, volume fraction and individual properties of two phases, allowing for welding thermal cycles. In EBW experiments the beam currents matched at 3 groups of welding speeds under condition of the invariable focus position, vacuum degree and accelerating voltage: $I_{\mathrm{b}}=65,110$ and $165 \mathrm{~mA}$ at $v_{\mathrm{w}}=4,12$ and $25 \mathrm{~mm} / \mathrm{s}$; welding line energy was $1050 \eta, 550 \eta$ and $396 \eta \mathrm{J} / \mathrm{mm}$, respectively (where $\eta$ is the efficiency factor, identified the same condition). The cross-sectional macrographs of the EB-welded joints at different heat input are shown in Figure 2. The width of weld metal increases with increasing of heat input from 396 to $1050 \mathrm{~J} / \mathrm{mm}$. It can be seen that all the fusion zones consist of coarse columnar dendritic grains, which are perpendicular to the fusion zone boundary. The reason is that during molten metal solidification, grains tend to grow in the direction of maximum heat extraction.

The effect of heat input on mechanical properties is presented in Figure 3. The test results expressed that the regular mechanical properties are of little difference, in despite of welding parameters differentiated in heat input and cooling rates. The correlation between mechanical properties of the TC21 alloy EB-welded joints and heat input is negligible. As so high power density, EBW excels in the ability to strict the heated region in no time. The rate of temperature

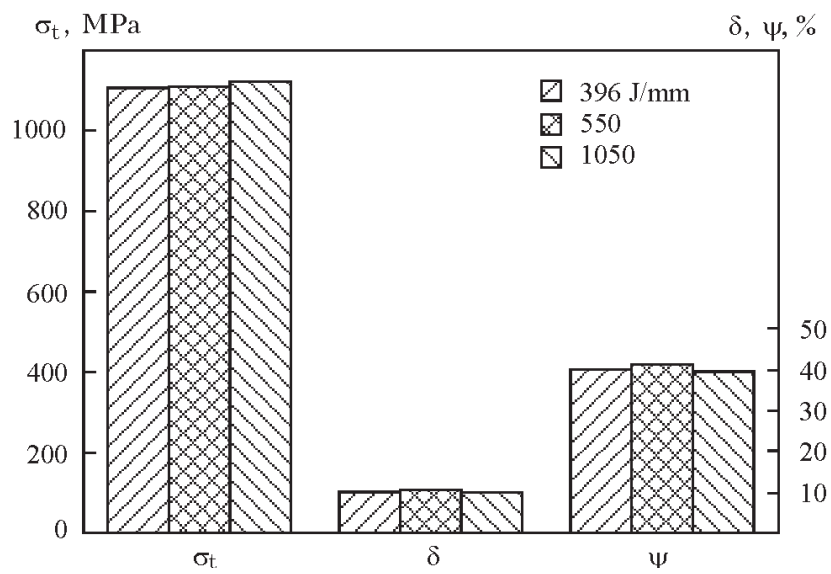

Figure 3. Mechanical properties of EB-welded joints at different heat input and cooling raise has distinct difference, despite of welding at varying parameters. Thus, the excellent mechanical properties of TC21 alloy EB-welded joints could be based on wide range of EBW parameters. This is in agreement with the Gleeble- simulated results.

EBW of $60 \mathrm{~mm}$ thick TC21 titanium alloy. For $60 \mathrm{~mm}$ thick TC21 alloy, the optimized EBW parameters were achieved using adequate trial welds with varying the parameters involved effecting weld character and defects. The beam focus position at $0.6 t$ beneath the surface and $400 \mathrm{~Hz}$ circular oscillation proved to be the most suitable for $v_{\mathrm{w}}=5 \mathrm{~mm} / \mathrm{s}$, accompanied by increased with more beam current and adjusting the slope-in/slope-out rates. At that, root spiking was suppressed [4], and satisfactory full penetration was achieved. Cross-sectional macrograph is shown in Figure 4. It can be seen that two sides of the weld boundary are parallel to each other, and the depth-to-width ratio is higher than 20:1.

The ultrasonic C-scan detection as a newly advanced method was used for NDT of welds, which has the advantage of high detection rate and high sensitivity for defects, such as lacks of penetration, lacks of fussion and pores. The ultrasonic $\mathrm{C}$-scan direction and image are shown in Figure 5. It can be seen that the quality of welds was satisfying, except for such defects as end crater and bead reinforcement.

The tensile, impact and fracture toughness properties of the duplex annealed joints and base metal are illustrated in Figure 6. Results indicate that the

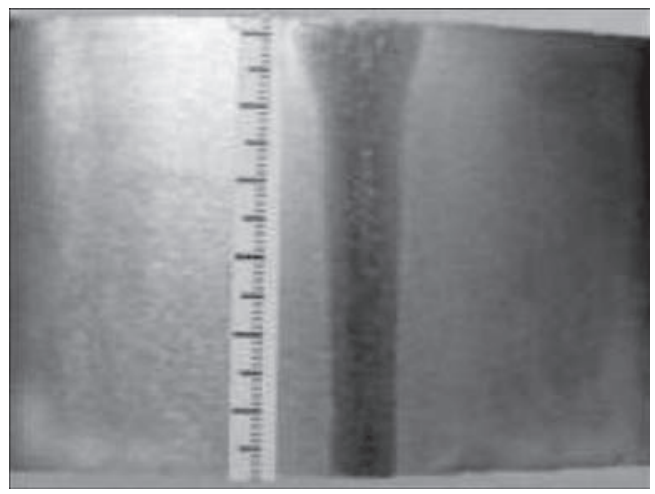

Figure 4. Cross-sectional macrograph of EB-welded joint $60 \mathrm{~mm}$ thick 

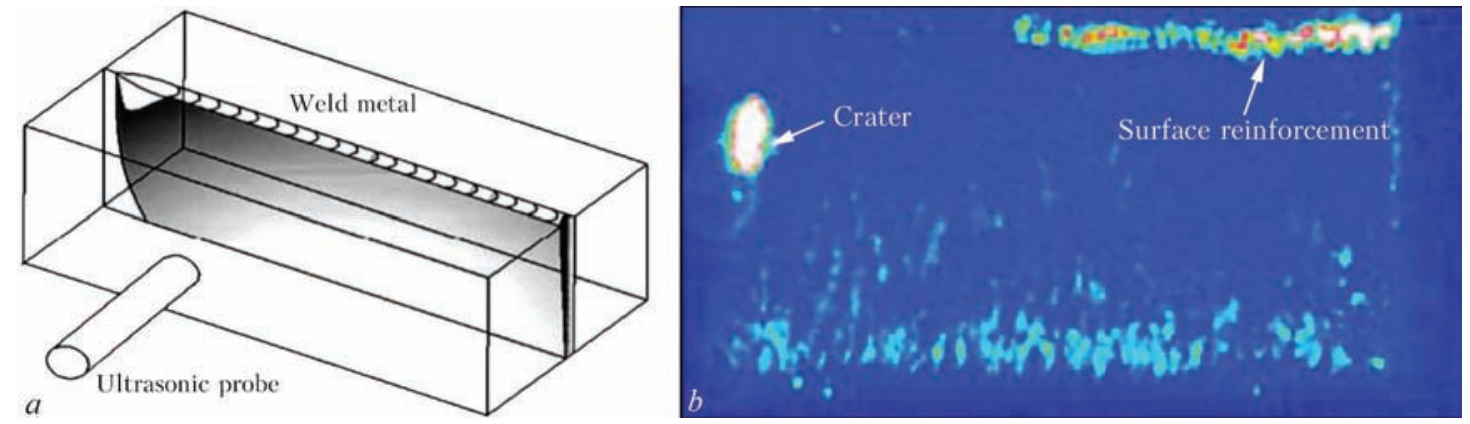

Figure 5. Ultrasonic C-scan of TC21alloy EB-welded joints 60 mm thick: $a$ - schematic diagram; $b$ - C-scan image

strength of welded joints is higher, while the ductility, impact and fracture toughness are slightly lower than those of base metal. It is noticeable that EB-welded joints show attractive fracture toughness. Their fracture toughness is $88.6 \mathrm{MPa} \cdot \sqrt{\mathrm{m}}$, reaching $92.5 \%$ of that of base metal.

In this study, high cycle fatigue strength was determined by staircase method and then, stress-life $(S-N)$ curves were obtained by grouping test method. $S-N$ curves for rupture probability of 0.5 and scatter of experimental data are presented in Figure 7. Experimental results were described as the maximum stress amplitude level versus the number of cycles. Both base metal and joints show a similar trend of increasing fatigue life with decreasing stress amplitude. The fatigue life of the welded joints appeared to be slightly higher than that of base metal at high stress amplitude $\left(\sigma_{\max }>690 \mathrm{MPa}\right)$, whereas this situation alternated at low stress amplitude $\left(\sigma_{\max }<690 \mathrm{MPa}\right)$. It can be seen that the conditional fatigue strength $\left(N_{f}=10^{7}\right)$ of the welded joint is $643 \mathrm{MPa}$, which is $\approx 98.3 \%$ of that of base metal (654 MPa), indicating that the fatigue endurance of the welded joints is excellent.

The $d a / d N-\Delta K$ curves in Figure 8 show that both the base metal and the joint in possession of lamellar structure gain the inferior crack propagation behavior. The fatigue crack growth rate $d a / d N$ versus stress intensity factor range $\Delta K$ for EB-welded joints and base metal is shown in Figure 9. It is apparent that $d a / d N-$ $\Delta K$ curves have three regions: threshold, linear and

$\sigma_{0.2}, \sigma_{\mathrm{t}}, \mathrm{MPa}$

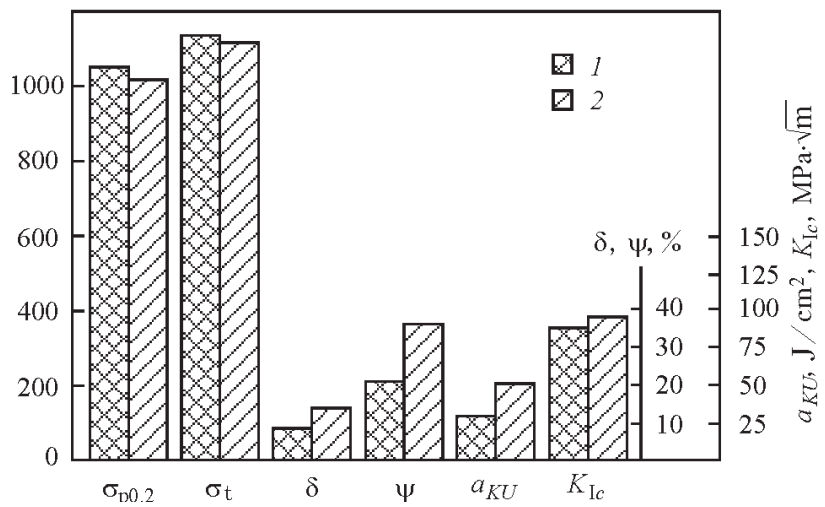

Figure 6. Tensile, impact and fracture toughness properties of Eb-welded annealed joints (1) and base metal (2)

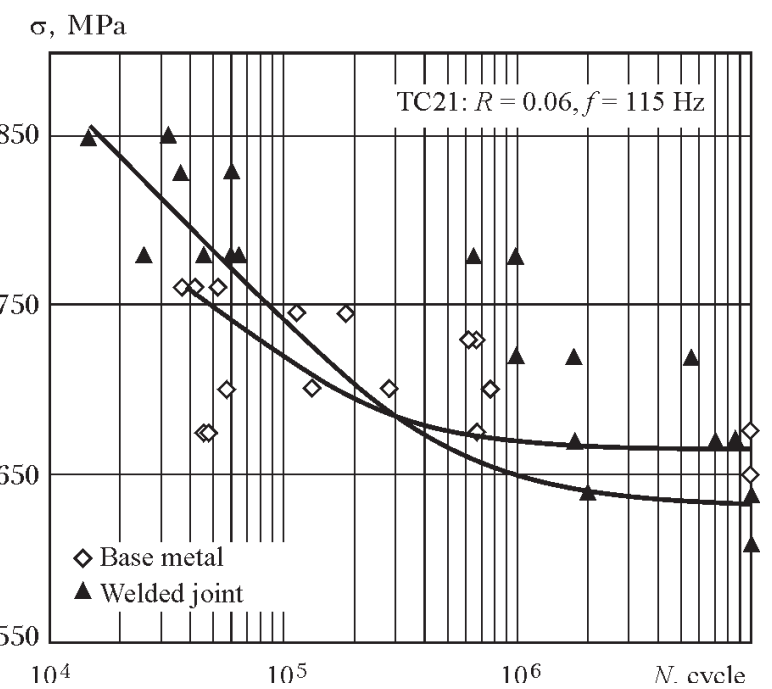

Figure 7. Fatigue test results and $S-N$ curves for WB-welded joints and base metal

unstable fracture ones. When $\Delta K<21 \mathrm{MPa} \cdot \sqrt{ } \mathrm{m}$, the fatigue crack growth rate of joint is lower than that of base metal at the same $\Delta K$ values. However, this tendency is reversed at high $\Delta K$ level.

Microstructures of TC21 duplex annealed alloy and weld metal are shown in Figure 9. The basketweave microstructure is characteristic for TC21

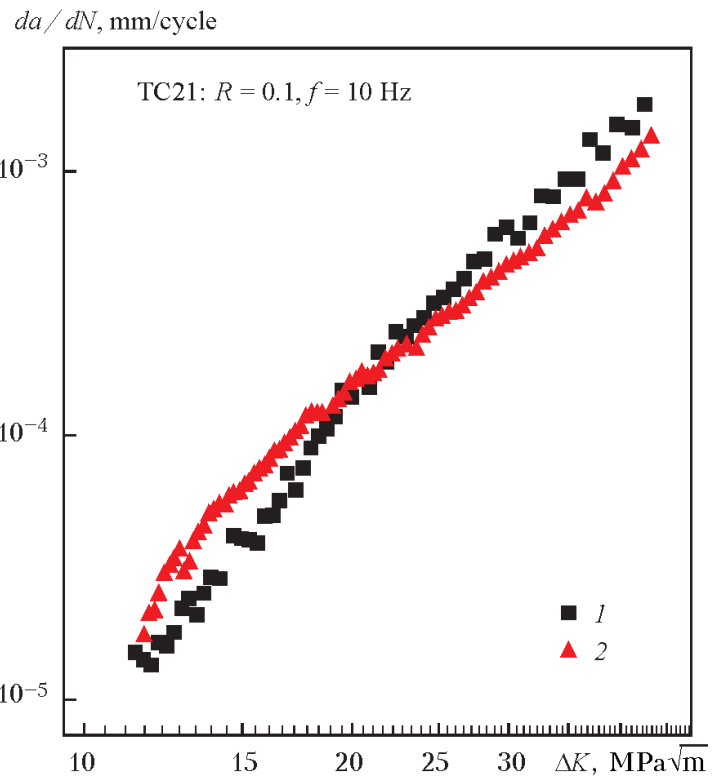

Figure 8. $d a / d N-\Delta K$ curves for EB-welded joints (1) and base metal (2) 


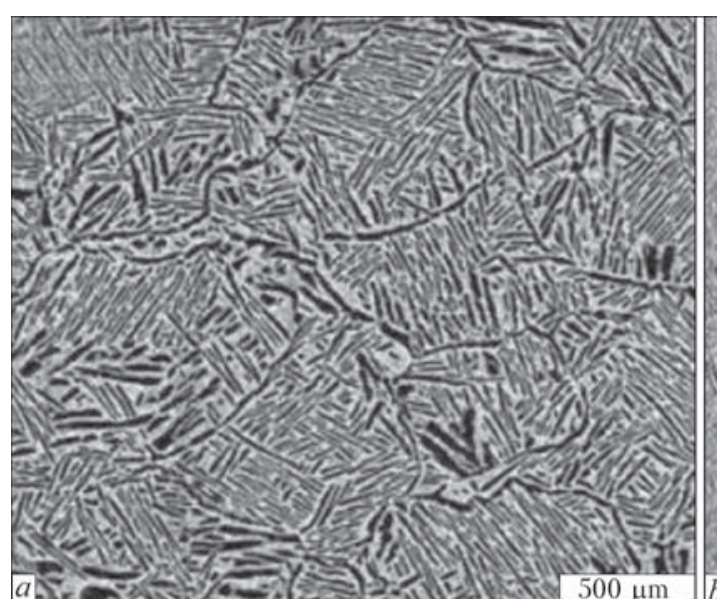

Figure 9. Microstructure of TC21 base ( $a$ ) and weld $(b)$ metal

titanium alloy at quasi- $\beta$ forging and duplex annealing. Due to high heating and cooling rate, the weld metal mainly consists of coarse columnar dendritic prior $\beta$-grains, which were made up of numerous finer acicular $\alpha$-martensite.

Compared with the base metal structure with relatively thick $\alpha$-lamellar, the finer acicular $\alpha$-martensite in the fusion zone possesses superior crack growth resistance at low $\Delta K<21 \mathrm{MPa} \cdot \sqrt{\mathrm{m}}$ level, that is in good agreement with data of work [5]. At high $\Delta K$, the thick $\alpha$-lamellar and large grain boundary area in base metal can offer more resistance to fatigue crack growth. That is because of crack branching or crack deflection, at which secondary crack occurs easily at $\alpha$-lamellar phase and grain boundaries. The crack growth path deflection changes the crack surface direction to the perpendicular direction of external force, that decreases the stress intensity factor at the crack tip and increases the length of the crack growth path. The crack branching or crack deflection as well as present of secondary crack made fracture surface more rough, and crack closure occurring at low loading increased the resistance to fatigue crack growth [6-8]. The difference in high cycle fatigue endurance and fracture toughness of the base metal and EB-welded joint can also be explained by the description above.

\section{Conclusions}

On the base of resuls obtained the following conclusions can be drawn from this study:

1. TC21 alloy is not sensitive to welding heat input and postweld cooling rates. The microstructure and mechanical properties of EB-welded joints can't be improved evidently by meliorating the welding parameters and welding line energy. The excellent mechanical properties of joints of TC21 alloy could be based on wide range of welding parameters.

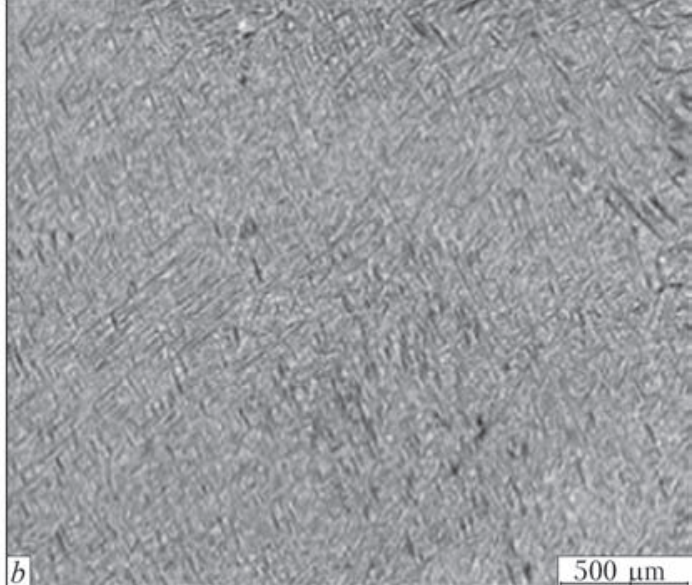

2. The tensile strength of joint is equal to that of base metal. The damage-tolerant properties of the joint, such as fracture toughness and resistance to fatigue crack propagation, are excellent, and fatigue behavior of joints is comparable to that of base metal.

3 . The basketweave structure of two-phase $\alpha++\beta$ titanium alloys compensates for the ability to improve resistance to crack initiation or short crack growth, and deflects its propagation path at the grain boundaries, on the stage of macrocrack or long crack propagation obviously, that decreases the crack propagation rate and improves fracture toughness and fatigue strength. The extent of thickness of lamellar microstructure and the dimension of grains account for difference of crack growth rate between base metal and EB-welded joints.

1. Ji-kui Zhang, Xiao-quan Cheng, Zheng-neng Li (2010) Total fatigue life prediction for Ti-alloys airframe structure based on durability and damage-tolerant design concept. Materials and Design, 31, 4329-4335.

2. Zhi-shou Zhu, Xin-nan Wang, Lu Tong et al. (2010) Research and application of damage tolerance titanium alloys for aeronautical use. Materials China, 29(5), 14-17.

3. Chun-xiao Cao (2002) Change of material selection criterion and development of high damage-tolerant titanium alloy. Acta Metallurg. Sinica, 38, 4-11.

4. Schiller, S., Heisig, U., Panzer, S. (1982) Electron beam technology, 315-318. John Wiley Publ.

5. Xin-nan Wang, Zhi-shou Zhu, Lu Tong et al. (2008) The influence of forging processing on fatigue crack propagation rate of damage-tolerant titanium alloy. Rare Metals Letters, 27(7), 12-16.

6. Nakajima, K., Terao, K., Miyata, T. (1998) The effect of microstructure on fatigue crack propagation of $\alpha+\beta$ titanium alloys in-situ observation of short fatigue crack growth. Materials Sci. and Eng. A, 243(1/2), 176-181.

7. Xiong, Y., Hu, X.X. (2012) The effect of microstructures on fatigue crack growth in Q345 steel welded joint. Fatigue \& Fracture of Eng. Mater. \& Structures, 35(6), 500-512.

8. Leyens, C., Peters, M. (2003) Titanium and titanium alloys, 160-161. John Wiley Publ. 